\title{
Leaching of heavy metals from waste rock and tailings from a $\mathrm{Cu}-\mathrm{Pb}-\mathrm{Zn}$ mine
}

\author{
JiLLIAN HELSER ${ }^{1,3 *}$, ANA LUPU ${ }^{1,2}$, VALÉRIE CAPPUYNS ${ }^{1,3}$ \\ ${ }^{1}$ Department of Earth and Environmental Sciences, KU \\ Leuven, 3001 Leuven, Belgium \\ (*correspondence: jillian.helser@kuleuven.be) \\ ${ }^{2}$ Department of Chemical Sciences, Life and \\ Environmental Sustainability, University of Parma, \\ 43121 Parma, Italy \\ ${ }^{3}$ Centre for Economics and Corporate Sustainability \\ (CEDON), KU Leuven, 1000 Brussels, Belgium \\ (valerie.cappuyns@kuleuven.be)
}

In the present study, mine tailings and waste rock originating from a $\mathrm{Cu}-\mathrm{Pb}-\mathrm{Zn}$ mine located in the Iberian pyrite belt, in southern Portugal, were investigated. Environmental risks posed by the mine waste were determined by linking the solid-phase speciation of heavy metals to the chemical leaching under different conditions. The mine waste was characterized, both chemically and mineralogically. The pseudo-total elemental concentration and quantitative mineralogical composition were determined with aqua regia digestion and x-ray diffraction (XRD), respectively. The mobility of heavy metals was determined by applying different leaching tests. More specifically, the US EPA Toxicity Characteristic Leaching Procedure (TCLP) and European EN 12457-2 leaching tests were performed to determine the toxicity of the waste in comparison with regulatory thresholds. Additionally, a $\mathrm{pH}$-dependent leaching test was applied at varying durations to study the effect of $\mathrm{pH}$ and time on the release of heavy metal(loid)s. The leachates were analyzed using ICP-OES for 23 trace elements. The residue remaining after the leaching tests was also saved for XRD analysis. The results of the leaching tests and mineralogical analysis were then evaluated in relation to geochemical calculations using PHREEQC. The TCLP test showed that the investigated samples were toxic in comparison with the regulatory thresholds and particularly high in $\mathrm{Cu}$. However, there was a rather high range of variability amongst the samples indicating the heterogeneity of the site. Results show that the tailings had a higher release of heavy metals than the waste rock. Overall, the $\mathrm{pH}$ was a key factor in the leaching of heavy metals and geochemical modeling proved to be a useful tool in further understanding the underlying processes controlling the release of heavy metals. 